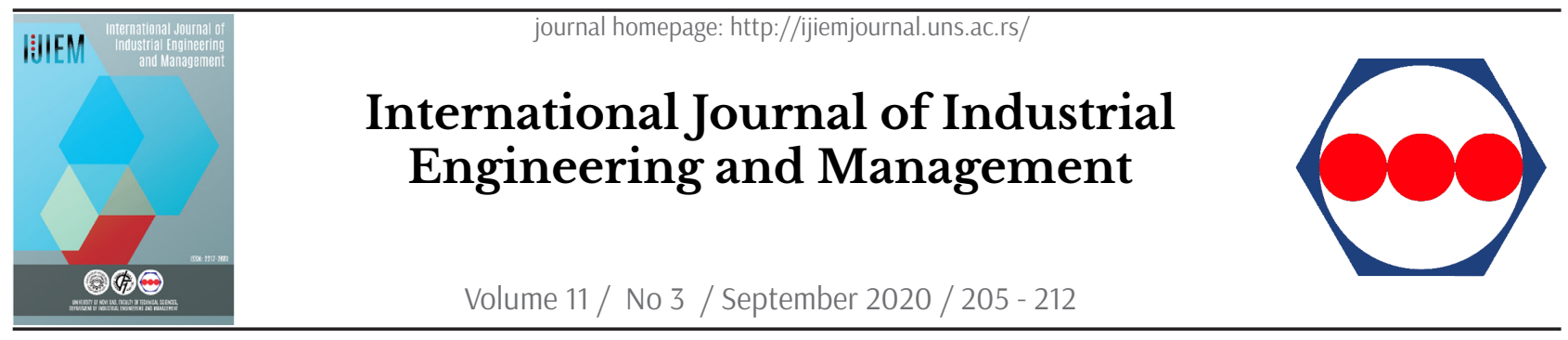

Original research article

\title{
Effects of human resources management on the manufacturing firm performance: Sustainable development approach
}

\author{
M. Dukić Mijatović, O. Uzelac*, A. Stoiljković \\ University of Novi Sad, Faculty of Economics in Subotica, Department of Management, Subotica, Serbia
}

\begin{abstract}
A B STR ACT
Sustainability is a necessity in today's business since long-term development cannot be achieved without embracing it. The fourth industrial revolution (i.e., Industry 4.0) that introduced the digital transformation of companies is pushing the industry towards sustainable development. Human resource management (HRM), as part of the Industry 4.0 concept, plays an essential role in the process of digital transformation, since employees represent the most flexible part of the production system. This paper aims to analyze the relationship between the implementation of HRM practices and the introduction of digital technologies in manufacturing firms. Additionally, the authors intend to determine whether the introduction of digital technologies enables the flexibility of the production system. For this purpose, data gathered through the European Manufacturing Survey (EMS) are used. The analyses are based on descriptive statistics and regression analysis. The results reveal that there is a significant positive relationship between the use of HRM practices and the implementation of digital technologies in manufacturing firms. Furthermore, firms that implemented digital technologies have a tendency to organize their production processes in a way that corresponds to trends in production imposed by the Industry 4.0 concept.
\end{abstract}

\section{ARTICLE INFO}

Article history:

Received May 6, 2020

Revised July 30, 2020

Accepted August 1, 2020

Published online August 6, 2020

Keywords:

Human Resource Management (HRM);

Industry 4.0;

Digital factory;

Sustainability;

Firm performance;

Flexibility;

*Corresponding author:

Ozren Uzelac

uzelacozren@ef.uns.ac.rs

\section{Introduction}

Sustainability represents a broad concept related to the various aspects of wellbeing for all [1]. The three main pillars of sustainability include the environmental, economic, and social perspectives of the development [2]. Sustainability is considered as a necessity since long-term growth cannot be achieved without embracing it [3]. This is in line with the industrial changes we are witnessing in the last decade. Namely, the fourth industrial revolution that introduced the digital transformation of businesses is pushing the industry towards sustainable develop- ment. This newly introduced concept, also referred to as Industry 4.0, is recently gaining much attention in the research community. One of the expected consequences of the Industry 4.0 implementation is to significantly contribute to environmental, economic, and social sustainability [4].

The implementation of Industry 4.0 can offer various advantages for manufacturers in terms of increased performance. One of the main characteristics of Industry 4.0 is to enable the production of complex products designed and produced according to customer specifications in small or even single batches [5], [6]. More particularly, the Industry 4.0 
concept offers the higher performance of manufacturing firms in terms of the increased flexibility of the production system. This is accomplished through the implementation of various digital technologies that enable real-time acquisition and analysis of the data, followed with the conversion of these data into useful information for the production system [7], [8].

The implementation of the technologies that are considered as enablers of Industry 4.0 is having a tendency to decrease human involvement in production processes [9]. This does not necessarily mean that the overall number of employees will decrease. On the contrary, digital transformation will negatively influence only the creation of lower-skilled jobs while at the same time creating numerous job opportunities in areas where the specific creative capabilities of employees are highly valued [10]. This is the point in which Human Resource Management (HRM) activities play a crucial role [11]. This is particularly important since organizational improvements, such as HRM activities, tend to complement technological improvements in manufacturing firms [12]. HRM should gain even more attention in the context of Industry 4.0 since employees represent the most flexible part of the system.

Considering all the above mentioned, this paper aims to shed light on the relationship between the implementation of HRM practices and the introduction of digital technologies in manufacturing firms. Furthermore, the authors intend to determine whether the introduction of digital technologies enables the flexibility of the production system. For this purpose, data gathered through the European Manufacturing Survey (EMS) are used. Moreover, the analyses are based on descriptive statistics and regression analysis.

The remainder of the paper has the following structure. Section 2 serves to present the theoretical background in the field, while Section 3 describes the proposed research model, data, and methods that were used in this research. Section 4 presents the research results and discussion. Finally, Section 5 contains the conclusion, including the identified limitations of the study and suggestions for further research.

\section{Theoretical background}

This part of the paper aims to provide a theoretical background for the research. More specifically, the issues related to Industry 4.0, sustainable development, and HRM practices will be addressed.

\subsection{Industry 4.0 and sustainable development}

Recently, the technological capacities of manufacturing firms have been on the rise. Advanced technologies have enabled companies to exchange information in real-time, to improve the speed and quality of their processes and to design products in innovative ways. The use of advanced technologies in an adequate way can provide firms with an advantage over their competitors. Consequently, the use of advanced technologies has become a crucial factor for companies to gain a competitive advantage [13]. Manufacturing firms are increasingly using digital technologies, which are considered as key enablers of Industry 4.0, to model, communicate, and execute operations in the production processes. These technologies enable the configuration, design, and control of the production system [14]. Based on the use of these technologies, it is possible to improve production or product assembly processes and to prepare automated procedures for production management. In addition, the use of digital technologies in manufacturing firms provides an opportunity for continuous improvement of work procedures and the elimination of errors in processes in an efficient manner [15].

Prior research shows that the implementation of Industry 4.0 technologies and the development of design principles of Industry 4.0 such as smart manufacturing and product personalization [16] has been related to the various sustainability opportunities [2], [7], [17]. Furthermore, Industry 4.0 is expected to contribute to job creation[18], including countless digitization-related job opportunities [10]. However, to achieve sustainable growth, it necessary to deep dive into the background of the term.

Sustainable growth is based on the idea of sustainability as a capacity for lasting existence. The generally accepted theory of sustainable development, some of which overlap with the concept of corporate social responsibility (environmental protection), comes mainly from the 1987 Brundtland Report [19]. An often-repeated definition of sustainable development is that it is a development that meets the needs of the present moment, without impairing the ability of future generations to meet their needs [19]. According to the other definition, corporate sustainability and, therefore, corporate social responsibility refers to the activities of an entity in a way that gives attention to problems of society and the environment and interacts with stakeholders [20]. Although the issue of corporate social responsibility is thought to have been 
considered in the 1930s and 1940s in the United States, it has only intensified since the Second World War [21]. However, corporate social responsibility is often erroneously reduced only to providing them with financial and other assistance (provision of services or delivery of goods) in case of natural disasters, as well as aiding certain social activities (sports, cultural, etc.). Legal theory points out that the food and packaging industries today are accused of obesity and poor nutrition [22]. When asked what can be considered socially responsible behavior, there are different understandings. In general, according to Campbell [23], socially responsible practice exists when businesses intentionally do nothing to harm the people they are in contact with or the local community in which they do business and if they repair the damage as soon as it is discovered or notified.

\subsection{HRM practices}

HRM is an essential function in manufacturing firms, especially in the Industry 4.0 era, when changes in production processes are very complex and rapid. Although the presence of digital technologies in production processes seems to have a tendency to reduce the number of workers on the shop floor, employees are still considered as the most flexible part of the system [11]. For this reason, it is necessary for manufacturing firms to invest in the development of their employees in order to maintain the quality of all processes on the appropriate level. On the one hand, it is necessary to pay attention to the satisfaction of employees since there is a lack of workforce that is able to respond to the demands of modern production, which involves the application of numerous advanced technologies. On the other hand, in order for employees to be able to follow and adapt to new trends in production, it is necessary to provide adequate training and other forms of their development. HRM is considered as one of the primary sources by which firms can shape the skills, abilities, behavior, and attitude of their employees and ensure that their activities are aligned with the firm's goals [24].

Firms need to design their training programs in a way that improves the innovative skills and learning of employees. In addition, firms should offer their employees different types of training to enable them to perform various jobs [25]. In this sense, the training that firms offer to their employees does not necessarily have to be directly related to their work but can be aimed at increasing the diversity of employee skills. Given the constant changes, employee training should be realized as a continuous process. Em- phasis should also be on teamwork, and mentoring should be a standard activity of managers. Moreover, employees should be trained to solve various problems they encounter and not just perform routine tasks [26].

Manufacturing firms should make a great effort in selecting the right candidates for each job, using extensive selection and recruitment procedures. In the process of selection and recruitment, firms should assess the target orientation of the candidate, which can be focused on learning or performance. In order to promote innovation and learning, firms should focus on candidates who are primarily learning-oriented. Since employees with a learning orientation prefer to deal with challenging tasks, they are interested in constantly improving and developing new skills and knowledge, thus enabling them to be involved in flexible job rotations [27].

Employee income should be based on their contribution to the firm. This contribution should be considered from the perspective of personal, group, and company performance. There should be a clear link between performance and rewards, as this way of rewarding fosters innovation and a desire to learn in the firm [26].

\subsection{Research questions}

In order to analyze the relationship between HRM practices, implementation of digital technologies, and performance of manufacturing firms in terms of increased flexibility, the following research questions are proposed:

- RQ1: What is the relationship between HRM practices and the implementation of digital technologies in manufacturing firms?

-RQ2: Does the implementation of digital technologies increase the flexibility of the production processes?

\section{Research model, data, and methods}

To answer the research questions developed based on the theoretical background, the research model presented in Figure 1, is proposed.

This research is based on the data collected under the international project European Manufacturing Survey (EMS). EMS is a survey organized by research institutes and universities across Europe with the focus on innovation in manufacturing firms that considers various aspects of manufacturing processes in a standardized and systematized way [28], [29]. The survey is carried out on a triennial basis 
and includes manufacturing firms (NACE Rev 2 codes from 10 to 33 ) with more than 20 employees. It is designed to be representative of all regions, manufacturing sectors, and firm sizes that constitute the population of interest. The EMS questionnaire contains detailed information on qualification and area distribution of the employees and a number of control variables, such as firm size or characteristics of the main product and of the production process [30]. The dataset used in this research is based on the 2018 data collection activities conducted among Serbian manufacturing firms. The dataset includes 240 firms from which about $46 \%$ are small firms ranging from 20 to 49 employees, another $43 \%$ of firms have between 50 and 249 employees representing medium-sized firms, and final $11 \%$ of the firms have more than 250 employees thus belonging to the group of large firms. The number and share of the firms in the sample based on the manufacturing sector they belong to is presented in Table 1 .

This research employed the part of the EMS survey relating to the use of human resource management practices, digital technologies, and production characteristics of manufacturing firms. More specifically, the respondents were asked which hu- man resource management practices and advanced digital technologies are implemented in their firms and what are the characteristics of their production processes. The list of human resource management practices, advanced digital technologies, and production characteristics that were used in this research is the outcome of expert opinion of EMS consortium members, firms that participated in the research and literature review [5], [31]-[34].

The HRM practices included in the model are the following [26], [31]:

-Instruments to promote staff loyalty (e.g., attractively designed responsibilities, offering learning opportunities, flexible working hours, child care)

- On-the-job training (e.g., job rotation, mentoring, coaching)

The digital technologies, also known as smart manufacturing technologies, are as follows [33], [35][37]:

- Mobile/wireless devices for programming and controlling facilities and machinery (e.g., tablets)

- Digital solutions to provide drawings, work schedules or work instructions directly on the

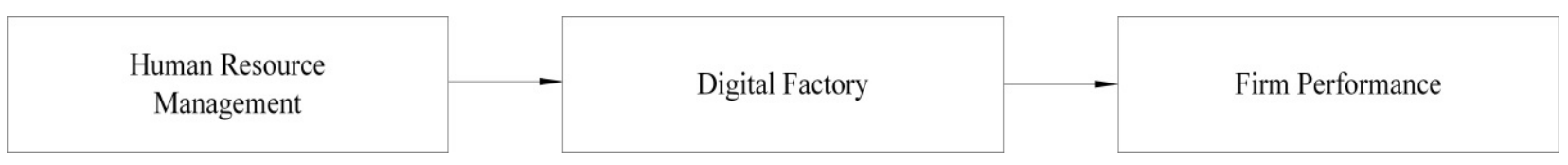

Figure 1. Proposed research model

Table 1. Number and share of firms based on the manu acturing sector

\begin{tabular}{llll}
\hline NACE & Manufacturing sector & $\begin{array}{l}\text { Number of firms in } \\
\text { the sample (n) }\end{array}$ & $\begin{array}{l}\text { Share of firms in } \\
\text { the sample (\%) }\end{array}$ \\
\hline 10 & Manufacture of food products & 39 & 16.3 \\
25 & Manufacture of fabricated metal products & 36 & 15.0 \\
22 & Manufacture of rubber and plastic products & 21 & 8.8 \\
28 & Manufacture of machinery and equipment n.e.c. & 15 & 6.3 \\
27 & Manufacture of electrical equipment & 15 & 6.3 \\
14 & Manufacture of wearing apparel & 14 & 5.8 \\
23 & Manufacture of other non-metallic mineral products & 11 & 4.6 \\
16 & Manufacture of wood and of products of wood & 11 & 4.6 \\
29 & Manufacture of motor vehicles, trailers and semi-trailers & 10 & 4.2 \\
31 & Manufacture of furniture & 9 & 3.8 \\
18 & Printing and reproduction of recorded media & 9 & 3.8 \\
15 & Manufacture of leather and related products & 7 & 3.0 \\
& Other & 43 & 17.9 \\
\hline
\end{tabular}


shop floor

- Software for production planning and scheduling (e.g., ERP system)

- Digital supply chain management

- Near real-time production control system (e.g., systems of centralized operating and machine data acquisition)

- Systems for automation and management of internal logistics (e.g., RFID)

- Product lifecycle management systems

- Virtual reality or simulation for product design or product development

Production characteristics employed for the measurement of the production process flexibility are the following [5], [31], [38]: Product development according to customers' specification, Standardized basic program incorporating customer-specific options, Standard program, Made-to-order, Assembly-to-order, Production to stock, Single-unit production, Small or medium batch production, Large batch production, Simple products, Products with medium complexity, and Complex products.

The authors have implemented these constructs to build the model, presented in Fig. 1, which was used to analyze the relationship between the implementation of HRM practices and the introduction of digital technologies and, consequently, the level of flexibility in manufacturing firms.

To analyze the relationship between HRM practices, digital technologies, and firm performance (i.e., flexibility), we employed descriptive statistics and linear regression. The relationship between the implementation of HRM practices and digital technologies is analyzed based on the results derived from linear regression. Consequently, the descriptive statistics were used to check the flexibility of the production system in those manufacturing firms that introduced digital technologies in their production processes.

\section{Results and discussion}

Linear regression is employed in order to give an answer to RQ1, which investigates the relationship between HRM practices and digital technologies. The breadth of the number of HRM practices and digital technologies is used for the analysis. The results are presented in Table 2.

The results show that there is a significant positive relationship between the use of HRM practices and the implementation of digital technologies in manufacturing firms. More precisely, if a firm has a tendency to nurture its employees and to give them opportunities for further development, than it is easier to introduce digital technologies in everyday processes. This is in line with prior research that claims that HRM plays an important role in the digitalization process since employees should be prepared for changes that Industry 4.0, along with the introduction of digital technologies in the manufacturing environment is bringing [12]. As a consequence, it is expected that the appropriate use of digital technologies in manufacturing processes, enhanced by the capabilities of employees, can increase the flexibility of a production system. Considering long-term effects, this strategy could secure the competitiveness and sustainability of a firm in a constantly changing market environment.

The results depicted in Table 3 serve to explain whether the introduction of digital technologies increases firm performance in terms of achieving higher flexibility of a production system (i.e., RQ2). The cross-tabulation analysis is employed to present the number of firms that introduced specific digital technology and have various production characteristics.

Based on the descriptive statistics, it is shown that firms that implemented digital technologies have a tendency to organize their production processes in a way that corresponds to trends in production im-

Table 2. Results of the linear regression

Digital Factory

Human Resource Management

$\mathrm{R}$

R2

$\mathrm{F}$

Sig

\section{$.324^{*}$}

0.324

0.105

27.912

0.000

Note: ${ }^{*} p<0.001$ 
posed by the Industry 4.0 concept. More particularly, firms that follow the digitalization strategy are able to produce small or even single batches of complex products that are designed and manufactured according to customer specifications. These results reveal that investment in human resources followed by the implementation of digital technologies enables higher flexibility of the production systems, thus increasing the competitiveness and sustainability of manufacturing firms that follow this trend [10].

\section{Conclusions}

This paper analyses the relationship between the implementation of HRM practices and the introduction of digital technologies as an important step for the introduction of the Industry 4.0 concept in manufacturing firms. Furthermore, the analysis is extended in order to determine whether the introduction of digital technologies enables the flexibility of the production system. For this purpose, data gathered through the EMS are used. The analyses are based on descriptive statistics and regression analysis. The results reveal that there is a significant positive relationship between the use of HRM practices and the implementation of digital technologies in manufacturing firms. Furthermore, firms that implemented digital technologies have a tendency to organize their production processes in a way that corresponds to trends in production imposed by the Industry 4.0 concept. The increased flexibility of the production system enables the production of complex products designed and produced according to customer specifications in small or even single batches.

This paper contributes to the literature in the field by finding the link between HRM practices, Industry 4.0 , and increased flexibility of the production sys- tem. These findings allow managers to build their strategies using the given information. Furthermore, our study shows the importance of both non-technological and technological aspects of manufacturing activities to achieve greater competitiveness and sustainability in a rapidly changing environment.

Our analyses rely on the data gathered from all manufacturing sectors, thus making the conclusions rather general. We can assume that focus on the specific sector or group of similar industries could yield different results. Therefore, we are calling for a more in-depth analysis of the problem imposed. Other aspects that diversify the sample, such as firm size, could be included in further research.

\section{Funding}

This work was supported by the Provincial Secretariat for Higher Education and Scientific Research of Autonomous Province of Vojvodina, Republic of Serbia, research project "Effects of corporate social responsibility in the field of human resources management on the performance and sustainability of organizations" [grant agreement number 142-4512482/2019-03].

\section{References}

[1] G. Beier, S. Niehoff, T. Ziems, and B. Xue, "Sustainability aspects of a digitalized industry - A comparative study from China and Germany,” Int. J. Precis. Eng. Manuf. - Green Technol., vol. 4, no. 2, pp. 227-234, 2017, doi: 10.1007/s40684-017-0028-8.

[2] S. S. Kamble, A. Gunasekaran, and S. A. Gawankar, "Sustainable Industry 4.0 framework: A systematic literature review identifying the current trends and future perspectives," Process Saf. Environ. Prot., vol. 117, pp. 408-425, 2018, doi: 10.1016/j.psep.2018.05.009.

[3] P. Glavič and R. Lukman, "Review of sustainability terms

Table 3. Production characteristics related to use of digital technologies

\begin{tabular}{lllllllllllll}
\hline & P1 & P2 & P3 & P4 & P5 & P6 & P7 & P8 & P9 & P10 & P11 & P12 \\
\hline T1 & 26 & 5 & 2 & 24 & 4 & 4 & 5 & 12 & 10 & 5 & 13 & 12 \\
T2 & 37 & 11 & 8 & 42 & 4 & 11 & 14 & 26 & 16 & 13 & 26 & 16 \\
T3 & 49 & 25 & 13 & 61 & 9 & 17 & 22 & 39 & 29 & 17 & 47 & 20 \\
T4 & 53 & 21 & 11 & 61 & 8 & 15 & 24 & 35 & 27 & 15 & 44 & 23 \\
T5 & 44 & 14 & 8 & 48 & 6 & 12 & 17 & 25 & 22 & 12 & 36 & 16 \\
T6 & 29 & 8 & 6 & 30 & 5 & 7 & 14 & 15 & 15 & 8 & 17 & 15 \\
T7 & 18 & 9 & 5 & 20 & 3 & 6 & 9 & 12 & 9 & 4 & 12 & 10 \\
T8 & 34 & 10 & 8 & 39 & 4 & 5 & 18 & 20 & 8 & 10 & 23 & 13 \\
\hline
\end{tabular}

Note: T1 - Mobile devices for programming and controlling; T2 - Use of digital solutions directly on the shop floor; T3 - ERP system; T4 - EDI; T5 - MES; T6 - RFID; T7 - PLM; T8 - Virtual Reality or simulation for product design or product development; P1 - Product development according to customers' specification; P2 - Standa dized basic program incorporating customer-specific options; P3 - Standard program; P4 - Made-to-order; P5 - Assembly-to-order; P6 - To stock; P7 - Single unit production; P8 - Small or medium batch; P9 - Large batch; P10 - Simple products; P11 - Products with medium complexity; P12 - Complex products; 
and their definitions," J. Clean. Prod., vol. 15, no. 18, pp. 1875-1885, 2007, doi: 10.1016/j.jclepro.2006.12.006.

[4] A. B. Lopes de Sousa Jabbour, C. J. C. Jabbour, M. Godinho Filho, and D. Roubaud, "Industry 4.0 and the circular economy: a proposed research agenda and original roadmap for sustainable operations," Ann. Oper. Res., vol. 270, no. 1-2, pp. 273-286, 2018, doi: 10.1007/s10479-018-2772-8.

[5] N. Medić, Z. Anišić, B. Lalić, U. Marjanović, and M. Brezocnik, "Hybrid fuzzy multi-attribute decision making model for evaluation of advanced digital technologies in manufacturing: Industry 4.0 perspective," Adv. Prod. Eng. Manag., vol. 14, no. 4, pp. 483-493, 2019, doi: 10.14743/apem2019.4.343.

[6] L. K. Grafmüller, S. Hankammer, S. Hönigsberg, and H. Wache, "Developing complex, mass-customized products in SME networks: Perspectives from co-creation, solution space development, and information system design,” Int. J. Ind. Eng. Manag., vol. 9, no. 4, pp. 215-227, 2018, doi: 10.24867/IJIEM-2018-4-215.

[7] S. Wang, J. Wan, D. Zhang, D. Li, and C. Zhang, "Towards smart factory for industry 4.0: A self-organized multi-agent system with big data based feedback and coordination," Comput. Networks, vol. 101, pp. 158-168, 2016, doi: 10.1016/j.comnet.2015.12.017.

[8] T. Hoffmann-Walbeck, "Smart factory: JDF and XJDF," J. Graph. Eng. Des., vol. 9, no. 1, pp. 5-9, 2018, doi: 10.24867/JGED-2018-1-005.

[9] Alasdair Gilchrist, "Industry 4.0: The Industrial Internet of Things,” Dep. Trade, Invest. Innov., p. 20, 2016, doi: 10.1007/978-1-4842-2047-4.

[10] D. Brougham and J. Haar, "Smart Technology, Artificial Intelligence, Robotics, and Algorithms (STARA): Employees' perceptions of our future workplace," J. Manag. Organ., vol. 24, no. 2, pp. 239-257, 2018, doi: 10.1017/jmo.2016.55.

[11] I. Korobaničová and N. Kováčová, "Human capital investment: Practices and measurement in Slovak enterprises,” Int. J. Ind. Eng. Manag., vol. 9, no. 3, pp. 139 146, 2018, doi: 10.24867/IJIEM-2018-3-139.

[12] H. Kagermann, W. Wahlster, and J. Helbig, "Recommendations for implementing the strategic initiative INDUSTRIE 4.0," Frankfurt, Germany, 2013.

[13] D. Reid and N. Sanders, Operations Management: An Integrated Approach. Hoboken, USA: John Wiley \& Sons, Inc., 2013.

[14] G. L. Tortorella and D. Fettermann, "Implementation of industry 4.0 and lean production in brazilian manufacturing companies,” Int. J. Prod. Res., vol. 56, no. 8, pp. 29752987, 2018, doi: 10.1080/00207543.2017.1391420.

[15] A. Stork et al., "Enabling virtual assembly training in and beyond the automotive industry," in Proceedings of the 2012 18th International Conference on Virtual Systems and Multimedia, VSMM 2012: Virtual Systems in the Information Society, 2012, pp. 347-352, doi: 10.1109/VSMM.2012.6365944.

[16] N. Suzić, E. Sandrin, S. Suzić, C. Forza, A. Trentin, and Z. Anišić, "Implementation guidelines for mass customization: A researcher-oriented view," Int. J. Ind. Eng. Manag., vol. 9, no. 4, pp. 229-243, 2018, doi: 10.24867/IJIEM-2018-4-229.

[17] L. S. Dalenogare, G. B. Benitez, N. F. Ayala, and A. G. Frank, "The expected contribution of Industry 4.0 technologies for industrial performance," Int. J. Prod. Econ., vol. 204, no. July, pp. 383-394, 2018, doi: 10.1016/j.ijpe.2018.08.019.

[18] C. B. Frey and M. A. Osborne, "The future of employment: How susceptible are jobs to computerisation?," Technol. Forecast. Soc. Change, vol. 114, pp. 254-280,
2017, doi: 10.1016/j.techfore.2016.08.019.

[19] G. H. Brundtland, "Report of the World Commission on Environment and Development: Our Common Future," Oslo, Norway, 1987.

[20] M. Van Marrewijk, "Concepts and Definitions of CSR and Corporate Sustainability: Between Agency and Communion,” J. Bus. Ethics, vol. 44, no. 2-3, pp. 95-105, 2003, doi: 10.1023/A:1023331212247.

[21] A. B. Carroll, "Corporate social responsibility: Evolution of a definitional construct," Bus. Soc., vol. 38, no. 3, pp. 268295, 1999, doi: 10.1177/000765039903800303.

[22] M. E. Porter and M. R. Kramer, "Strategy \& society: The link between competitive advantage and corporate social responsibility," Harv. Bus. Rev., vol. 84, no. 12, pp. 78-92, 2006.

[23] J. L. Campbell, "Why would corporations behave in socially responsible ways? An institutional theory of corporate social responsibility," Acad. Manag. Rev., vol. 32, no.3,pp.946-967,2007, doi: 10.5465/AMR.2007.25275684.

[24] A. Benešová and J. Tupa, "Requirements for Education and Qualification of People in Industry 4.0," Procedia Manuf., vol. 11, pp. 2195-2202, 2017, doi: 10.1016/j.promfg.2017.07.366.

[25] M. Bakator, N. Petrović, S. Borić, and N. Đalić, "Impact of human resource management on business performance: A review of literature," J. Eng. Manag. Compet., vol. 9, no. 1, pp. 3-13, 2019, doi: 10.5937/jemc1901003b.

[26] I. Ma Prieto and M. Pilar Perez-Santana, "Managing innovative work behavior: the role of human resource practices,” Pers. Rev., vol. 43, no. 2, pp. 184-208, 2014.

[27] A. Fazlzadeh and M. R. Khoshhal, "Strategic Human Resource Practices and Innovation Performance - The Mediating Role of Knowledge Management Capacity," SSRN Electron. J., 2012, doi: 10.2139/ssrn.1672243.

[28] B. Lalic, T. Todorovic, N. Medic, B. Bogojevic, D. Ciric, and U. Marjanovic, "The Impact of InterOrganizational Cooperation on R\&D Expenditure of Manufacturing Companies,” Procedia Manuf., vol. 39, pp. 1401-1406, 2019, doi: 10.1016/j.promfg.2020.01.315.

[29] B. Lalic, N. Medic, M. Delic, N. Tasic, and U. Marjanovic, "Open innovation in developing regions: An empirical analysis across manufacturing companies,” Int. J. Ind. Eng. Manag., vol. 8, no. 3, pp. 111-120, 2017.

[30] U. Marjanovic, B. Lalic, N. Medic, J. Prester, and I. Palcic, "Servitization in manufacturing: role of antecedents and firm characteristics," Int. J. Ind. Eng. Manag., no. 2, pp. 133-144, Jun. 2020, doi: 10.24867/IJIEM-2020-2-259.

[31] N. Medic, U. Marjanovic, N. Zivlak, Z. Anisic, and B. Lalic, "Hybrid Fuzzy MCDM Method for Selection of Organizational Innovations in Manufacturing Companies," in TEMS-ISIE 2018 - 1st Annual International Symposium on Innovation and Entrepreneurship of the IEEE Technology and Engineering Management Society, 2018, doi: 10.1109/TEMS-ISIE.2018.8478445.

[32] B. Lalic, S. Rakic, and U. Marjanovic, "Use of industry 4.0 and organisational innovation concepts in the Serbian textile and apparel industry," Fibres Text. East. Eur., vol. 27, no. 3, pp. 10-18, 2019, doi: 10.5604/01.3001.0013.0737.

[33] B. Lalic, Z. Anisic, N. Medic, N. Tasic, and U. Marjanovic, "The impact of organizational innovation concepts on new products and related services," in International Conference on Production Research - ICPR, 2017, pp. 110-115.

[34] B. Lalic, U. Marjanovic, S. Rakic, M. Pavlovic, T. Todorovic, and N. Medic, "Big data analysis as a digital service: Evidence form manufacturing firms," in Lecture Notes in Mechanical Engineering, 2020, pp. 263-269, doi: 10.1007/978-3-030-46212-3_19.

[35] D. Berić, D. Stefanović, B. Lalić, and I. Ćosić, "The implementation of ERP and MES Systems as a support to 
industrial management systems,” Int. J. Ind. Eng. Manag., vol. 9, no. 2, pp. 77-86, 2018.

[36] U. Marjanovic, S. Rakic, and B. Lalic, "Digital Servitization:

The Next 'Big Thing' in Manufacturing Industries," in Advances in Production Management Systems. Production Management for the Factory of the Future, 2019, pp. 510517, doi: 10.1007/978-3-030-30000-5_63.

[37] U. Marjanovic, B. Lalic, V. Majstorovic, N. Medic, J. Prester, and P. Iztok, "How to Increase Share of Product-Related Services in Revenue? Strategy Towards Servitization," in Advances in Production Management Systems. Smart Manufacturing for Industry 4.0, 2018, vol. 536, pp. 57-64, doi: 10.1007/978-3-319-99707-0.

[38] R. Koren and I. Palčič, "The impact of technical and organisational innovation concepts on product characteristics.," Adv. Prod. Eng. Manag., vol. 10, no. 1, pp. 27-39, 2015. 